\title{
North Sea herring population structure revealed by microsatellite analysis
}

\author{
Stefano Mariani ${ }^{1,6, *}$, William F. Hutchinson ${ }^{1}$, Emma M. C. Hatfield ${ }^{2}$, \\ Daniel E. Ruzzante ${ }^{3}$, E. John Simmonds ${ }^{2}$, Thomas G. Dahlgren ${ }^{4}$, Carl Andre ${ }^{4}$, \\ Jennifer Brigham ${ }^{1}$, Else Torstensen ${ }^{5}$, Gary R. Carvalho ${ }^{1,7}$ \\ ${ }^{1}$ Molecular Ecology \& Fisheries Genetics Laboratory, Department of Biological Sciences, University of Hull, Hull HU6 7RX, UK \\ ${ }^{2}$ FRS Marine Laboratory Aberdeen, PO Box 101, Victoria Road, Aberdeen AB11 9DB, UK \\ ${ }^{3}$ Department of Biology, Dalhousie University, Halifax, Nova Scotia B3H 4J1, Canada \\ ${ }^{4}$ Department of Marine Ecology, Göteborg University, Tjärnö Marine Biological Laboratory, 45296 Strömstad, Sweden \\ ${ }^{5}$ Institute of Marine Research, Research Station Flødevigen, 4817 His, Norway \\ ${ }^{6}$ Present address: School of Biological and Environmental Science, University College Dublin, Belfield, Dublin 4, Ireland \\ ${ }^{7}$ Present address: School of Biological Sciences, University of Wales Bangor, Bangor, Gwynedd LL57 2UW, UK
}

\begin{abstract}
The Atlantic herring Clupea harengus has played a pivotal role in the formulation of ideas relating to population structuring in marine fishes, yet considerable uncertainty remains as to the extent to which phenotypic and genetic differentiation coincide in such a highly mobile species. In this study, we examined genetic population structure across the major herring spawning aggregations in the North Sea and adjacent waters over 2 years, 2002 and 2003. We analysed 1660 spawning individuals across 9 microsatellite loci. Data were analysed using several approaches, taking into account the effect of location, year-class and sex, as well as pooling all individuals together, making no assumption as to the number of populations present in the data set. The results suggest the presence of a genetically homogeneous unit off Northern Scotland, and a temporally stable pattern of isolation by distance determined predominantly by the divergence of the English Channel samples and, in 2003, by the Norwegian spring spawners. Our data suggest that the current view of North Sea herring as a unit-stock might be adequate, but confirm the considerable degree of demographic independence of the herring populations in the English Channel. Despite major recent population collapses, genetic data indicated no evidence of bottlenecks affecting the genetic diversity of extant North Sea herring populations. Finally, despite evidence of weak population structuring, we discuss the risks of underestimating population differentiation in marine fish of large population sizes, and with reference to herring population history and dynamics, we attempt to reconcile the existing theories on herring population structure.
\end{abstract}

KEY WORDS: Clupea harengus · Marine fish $\cdot$ Genetic structure $\cdot$ Isolation by distance $\cdot$ Age class · Metapopulation $\cdot$ Population size

\section{INTRODUCTION}

Despite a plethora of genetic studies on marine fishes, there remains a high degree of uncertainty as to the nature and extent of temporal and spatial population structuring in highly mobile, commercially exploited species (Waples 1998, Smedbol et al. 2002,
Kritzer \& Sale 2004). The paradigm of high dispersal and low genetic differentiation in such fishes (Carvalho \& Hauser 1994, Hauser \& Ward 1998) is being increasingly challenged as more appropriate sampling methods and sensitive molecular markers reveal finescale structuring in hitherto presumed panmictic populations (Ruzzante et al. 1998, 1999, Hutchinson et al. 
2001, Wirth \& Bernatchez 2001, Knutsen et al. 2003, Nielsen et al. 2004, O'Reilly et al. 2004). Data on the extent of such structuring and its determinants are central to our ability to manage and conserve declining stocks and their ecosystems (Palumbi 2003), and are also fundamental for predicting responses to continued harvesting and environmental change, especially in cases of relatively small effective population size (Hauser et al. 2002, Turner et al. 2002, Hutchinson et al. 2003, Hoarau et al. 2005).

Even with the long tradition of research on the general biology, ecology and genetics of Atlantic herring Clupea harengus L. (Blaxter \& Hunter 1982, Whitehead 1985), there is as yet no general agreement as to how herring populations are spatially and temporally structured. Cushing (1967) comprehensively reviewed the differences in spawning time, age- and size-atmaturity and other phenotypically measurable traits among herring populations in the NE Atlantic, grouping them into different 'races' and 'stocks', each dependent on their respective oceanic production cycle. Zijlstra (1969) also presented meristic and morphometric data to support the division of North Sea autumnspawning herring into 3 distinct stocks: 'Buchan', 'Banks' and 'Downs' herring, spawning respectively in the NW North Sea, the Central North Sea and the English Channel. However, it was emphasized that such heterogeneity might not have been underlain by genetic differences among groups (Cushing 1967). Iles \& Sinclair (1982) introduced the 'discrete population concept', based on the strong phenotypic variation in Atlantic herring, subdividing the species into several, locally adapted, distinct populations with independent life-histories. Smith \& Jamieson (1986) proposed the alternative and opposing 'dynamic balance concept', which assumes extensive genetic exchange and lack of population differentiation. More recently, McQuinn (1997) attempted to reconcile these 2 views under a metapopulational model (sensu Hastings \& Harrison 1994), whereby the extent of spatial structure among sub-populations depended upon patterns of temporal change in the entire metapopulation.

Morphology-based descriptors are strongly influenced by the physical environment, and recent evidence suggests that life-history traits in Atlantic herring may result mostly from phenotypic plasticity (Engelhard \& Heino 2004). Furthermore, tagging studies on Atlantic herring have been restricted in spatial and temporal scale (Anonymous 1975, Wheeler \& Winters 1984), while genetic techniques in the 1980s and early 1990s (i.e. allozymes, mtDNA restriction fragment length polymorphisms) tended to have limited power to detect population differentiation in highly mobile species of large census size (Kornfield et al. 1982, Grant 1984, Ryman et al. 1984, Turan et al. 1998).
Recently, the application of highly variable microsatellite DNA markers has proven to be informative for detecting subtle genetic structuring in Atlantic herring in the western Atlantic (McPherson et al. 2004) and sub-Arctic waters (Shaw et al. 1999), but findings thus far have not identified putative underlying causes or the most applicable population model for the species. The elucidation of such aspects is central to our understanding of not only population connectivity in the sea, but also impacts on the utility of the stock concept in fisheries management.

Herein, we present a comprehensive microsatellite analysis of herring spawning aggregations in the North Sea and adjacent waters. We examine the shortterm temporal stability through re-sampling over consecutive years, and assess whether year-class structure and sex-bias can affect population genetic structure. Furthermore, we examine the impact of the documented recent population collapses (Nichols 2001) on the genetic diversity of contemporary North Sea herring and discuss the potential demographic processes underlying the observed patterns. The results are considered in relation to North Sea herring population dynamics, life-history variation and population history, and attempt to reconcile current views of herring population structure.

\section{MATERIALS AND METHODS}

Sampling. Samples of Atlantic herring were collected across the major spawning aggregations known to exist around the North Sea and adjacent waters (Fig. 1) at different times of the year, using both commercial and research vessels. Fish were collected over 2 successive years, 2002 and 2003, to assess the shortterm temporal stability of spatial genetic variation. Approximately 100 randomly chosen fish from each sample were analysed genetically (see Table 1).

Sampling was designed to target spawning fish on their spawning grounds (see Table 1) in order to prevent potential non-spawning migrants from masking genetic differences among locales. Thus, only herring of gonadal maturity Stage 6 ('ripe-and-running') were genetically assayed, with the exception of the Møre sample in 2003 (MR03: Fig. 1), which included $53 \%$ of individuals at Stage 5.

For each sample, fish were collected and examined across the size range caught, to reflect both the size and age distribution in the population. Age was estimated by counting the number of otolith winter rings.

A sample of western Atlantic herring spawners from Nova Scotia, Canada (Trinity Ledge, as described in McPherson et al. 2004) was also assayed and compared to North Sea data. 


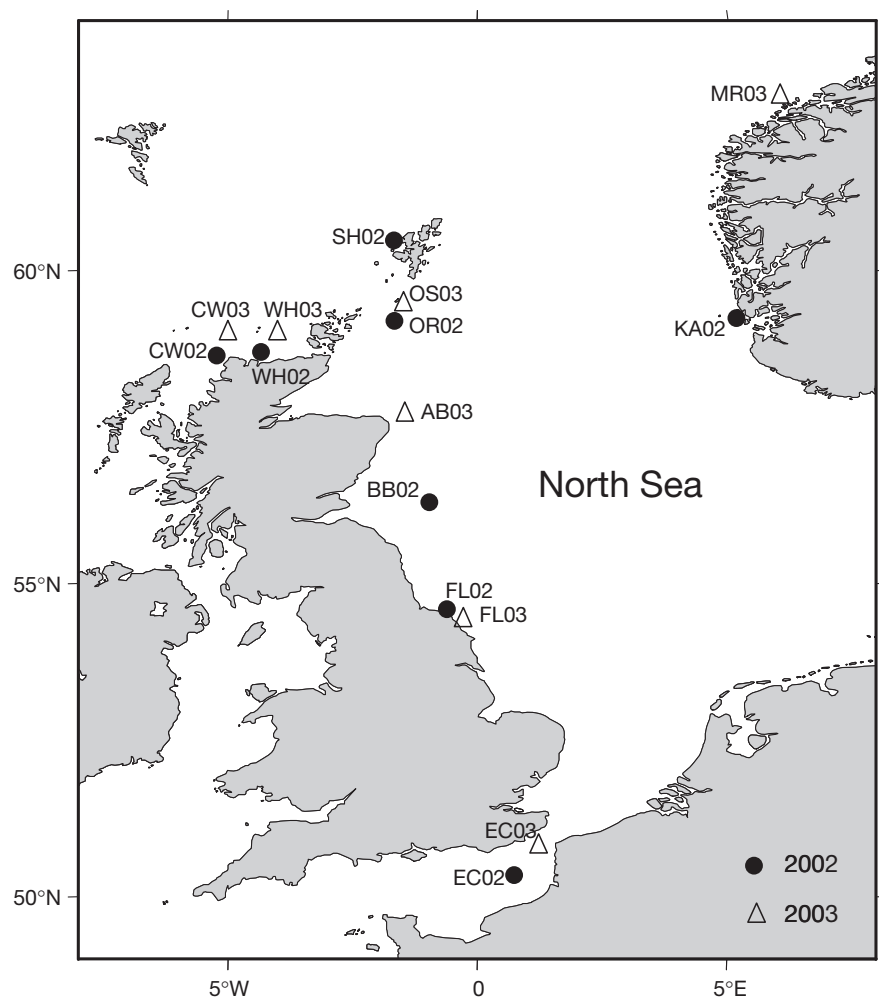

Fig. 1. Clupea harengus. Spawning herring samples analysed. Sample codes as in Table 1

Laboratory analyses. Genomic DNA was extracted from ethanol-preserved finclips using the HotSHOT method (Truett et al. 2000). Genetic variation within and among samples was assessed through PCR amplification of 9 tetranucleotide microsatellite loci: cha1017, cha1020, cha1027, cha1202, isolated from Atlantic herring (McPherson et al. 2001) and cpa101, cpa111, сра112, сра113, сра114, isolated from Pacific herring Clupea pallasi (Olsen et al. 2002). Another locus, cpa106 (Olsen et al. 2002) was also initially employed, but later excluded (see 'Results').

Microsatellite alleles were sized on 6\% acrylamide gels using Pharmacia ALFexpress ${ }^{\circledR}$ automated sequencers.

Statistical analyses. We tested the potential presence of null alleles and scoring errors due to stuttering and large allele drop-out using MICRO-CHECKER (van Oosterhout et al. 2004). Deviations from HardyWeinberg equilibrium across all loci and populations were assessed using Weir \& Cockerham's (1984) estimator of standardised genetic variance within populations, $F_{\mathrm{IS}}$ and tested through the exact test implemented in GENEPOP 3.3 (Raymond \& Rousset 1995), using the Markov chain method (100 batches of 1000 iterations).

Overall levels of population subdivision and differentiation among samples were assessed using Weir \&
Cockerham's (1984) estimator of standardised genetic variance between populations, $F_{\mathrm{ST}}(\theta)$, as implemented in GENETIX 4.04 (Belkhir et al. 2000), and the significance levels of pairwise comparisons were tested using 10000 permutations. Consistency of $F_{\mathrm{ST}}$ estimates across loci was tested through a 'jackknife' resampling procedure, and the possible association between locus polymorphism and differentiation detection power (O'Reilly et al. 2004) was tested by examining the relationship between $F_{\mathrm{ST}}$ and single locus allelic richness $R$ (El Mousadik \& Petit 1996).

Since various genetic measures respond differently to effective population size, mutation rate, mutation model and migration (Kalinowski 2002), we compared the $F_{\mathrm{ST}}$-based results to the patterns of genetic structure obtained with 2 other commonly used parameters: $D_{\mathrm{S}}$ (Nei 1978), which increases linearly with time and is independent of population size, and $R_{\mathrm{ST}}$ (Slatkin 1995), an analogue of $F_{\mathrm{ST}}$ that accounts for variance in allele size and suits genetic markers following a strictly stepwise mutation model (SMM) (i.e. each mutation creates a new allele either by adding or deleting a single repeated unit of the microsatellite). GENETIX 4.04 (Belkhir et al. 2000) was used to calculate $D_{\mathrm{S}}$ and Rst-CALC 2.2 (Goodman 1997) was employed for $R_{\mathrm{ST}}$ computation. Non-metric multidimensional scaling (MDS, Statistica 5.1, StatSoft 1996) was used to compare genetic distance ordinations

The relationship between genetic differentiation and geographical distance was explored by plotting the pairwise values of $F_{\mathrm{ST}} /\left(1-F_{\mathrm{ST}}\right)$ against natural logtransformed data of linear shortest sea-distance in $\mathrm{km}$ (Slatkin 1993, Rousset 1997). The significance of correlation between genetic and geographical matrices was tested by Mantel tests (Mantel 1967), using Mantel 2.0 (A. Liedloff ${ }^{\odot}$ 1999). The analysis was performed separately for samples collected in 2002 and 2003. Within each year, the same Mantel tests were also performed using male and female spawners separately, in order to test whether any subtle structuring might be accounted for by sex-biased dispersal. The Canadian sample was never included in these analyses, as the tests were specifically conducted to investigate isolation-by-distance in the North Sea area.

Subsequently, herring were grouped by year-class within each geographical sample, and where subsamples comprised at least $\sim 30$ individuals (13 subsamples in 2002 and 16 in 2003: see Table 1), they were compared using conventional $F_{\mathrm{ST}}$. Hierarchical analysis of molecular variance (AMOVA; Excoffier et al. 1992) was then used to partition genetic variance between subsamples within groups $\left(F_{\mathrm{SC}}\right)$ and among groups $\left(F_{\mathrm{CT}}\right)$. We compared 2 different 'group structures' in both years: one where groups were identified by year-classes (pre-1998, 1998, 1999, 2000) and one 
where groups corresponded to the 3 traditional North Sea herring spawning stocks (Nichols 2001): Northern North Sea ('Buchan' herring), Central North Sea ('Banks' herring) and English Channel ('Downs' herring) (Table 1). The Norwegian samples were omitted from this particular analysis because of the lack of comparable year-classes. Significance levels of $F_{\mathrm{SC}}$ and $F_{\mathrm{CT}}$ were tested using 1000 random permutations (ARLEQUIN Version 2.000: Schneider et al. 2000).

Conventional $F_{\mathrm{ST}}$ analysis was also conducted to assess the overall spatial genetic structure within each different year-class present in each sampling year, and test whether our data were consistent with Corten's (2002) view that the more philopatric older spawners may promote divergence among locations, while strong, non-philopatric first-time spawning year-classes should have an homogenising effect.

We also explored the genetic structure present in the data set without making any assumption as to the number of populations sampled, using PARTITION 1.1 (Dawson \& Belkhir 2001). The software estimates the posterior probability distribution of the partition of a sample of individuals, based on a Metropolis-Hasting Markov chain Bayesian calculation. When the Markov chain reaches equilibrium, an estimate of the most probable number of populations in the sample $(K)$ is taken, from the maximum point value of the posterior probability $(P)$, for each value of the number of possible source populations. We conducted the analysis on both 2002 and 2003 data sets separately, setting the number of possible source populations at $K=4$ (Buchan, Banks, Downs and Norwegian spring spawners). We ran 40000 iterations (10 cycles between each iteration). The number of iterations to be discarded ('burn-in') was inferred by checking the plot trend of the loglikelihood of the partition against the number of the observations of the Markov chain (Dawson \& Belkhir 2001); the first 10000 iterations were then discarded.

Finally, in order to explore the impact of recent population collapses (ICES 2004) on North Sea herring genetic variability, we first calculated Garza \& Williamson's (2001) $M$-ratio of the number of alleles to the allelic range across all loci and compared the value to a simulated distribution of $M$ in a population at equilibrium, computed using M_P_VAL (http://santacruz. nmfs.noaa.gov/staff/carlos_garza/software.php). Additionally, we used the approach implemented in Bottleneck 1.2 (Piry et al. 1999), which compares the observed gene diversity ( $H_{\mathrm{E}}$, as measured by Nei's [1987], unbiased expected heterozygosity) with the heterozygosity expected at equilibrium $\left(H_{\text {eq }}\right)$, based on the observed number of alleles $(k)$ and the sample size, to assess whether a genetic bottleneck had taken place. In populations that have experienced a recent reduction in effective population size, the allelic number declines at a faster rate than heterozygosity, and thus in a recently bottlenecked population, $H_{\mathrm{E}}$ is expected to be higher than $H_{\text {eq }}$. Significant deviations between $H_{\mathrm{E}}$ and $H_{\text {eq }}$ were tested using Wilcoxon's sign rank test and, qualitatively, by checking the presence of a mode-shift from a normal L-shaped distribution of allelic frequencies (Luikart et al. 1998). Analyses were performed on all samples pooled as well as on separate age classes, and tests were carried out assuming an 'infinite allele model' (IAM), as well as a 'two-phase mutation model' (TPM) with $90 \%$ one-step mutations, which is believed to represent a more realistic mutation model for most microsatellite markers (Di Rienzo et al. 1994).

\section{RESULTS}

Using MICRO-CHECKER, we detected evidence of null alleles at only 1 locus, cpa106 (Olsen et al. 2002), which was excluded from all further analyses. Levels of genetic variability were similar across all samples (Table 1). Average heterozygosity ranged between 0.783 and 0.842 ; the mean number of alleles per locus ranged from 15.9 to 17.7 in the North Sea (15.2 in the sample from Canada), and allelic richness $(R)$ values (Table 1) proved very homogeneous across samples. Only 10 out of 144 possible $F_{\text {IS }}$ values across loci and/or samples indicated a significant heterozygote deficiency. However, no population- or locus-specific trends were identified (Table 1).

\section{Spatial analysis over 2 years}

The overall $F_{\mathrm{ST}}$ value across all populations and loci was low but significant $\left(0.0011 ; \mathrm{p}<0.001 ; F_{\mathrm{ST}}=0.0009\right.$ if the Canadian sample is removed, Table 2) and jackknife $F_{\mathrm{ST}}$ estimates were very consistent across loci (Table 2). No association was found between allelic richness and $F_{\text {ST }}(r=-0.2 ; \mathrm{p}=0.54)$. Although the sample from Canada (Nova Scotia) was one of the most divergent populations (Table 3), its level of differentiation from the North Sea was of the same order of magnitude as that observed within the North Sea (Table 3). No significant $F_{\mathrm{ST}}$ values were found in any spatial and/or between-year pairwise comparison involving northern North Sea collections (Cape Wrath, Whiten Head, Orkney, Shetland) (Table 3).

MDS ordinations of the spatial patterns of genetic variation among samples from both years (Fig. 2), show a clustering of samples around the intercept, highlighting the absence of markedly distinct groups. $F_{\mathrm{ST}^{-}}$and $D_{\mathrm{S}}$-based ordinations provide similar results (Fig. 2a,b), with all northern North Sea populations grouped together, and Nova Scotian, English Channel 


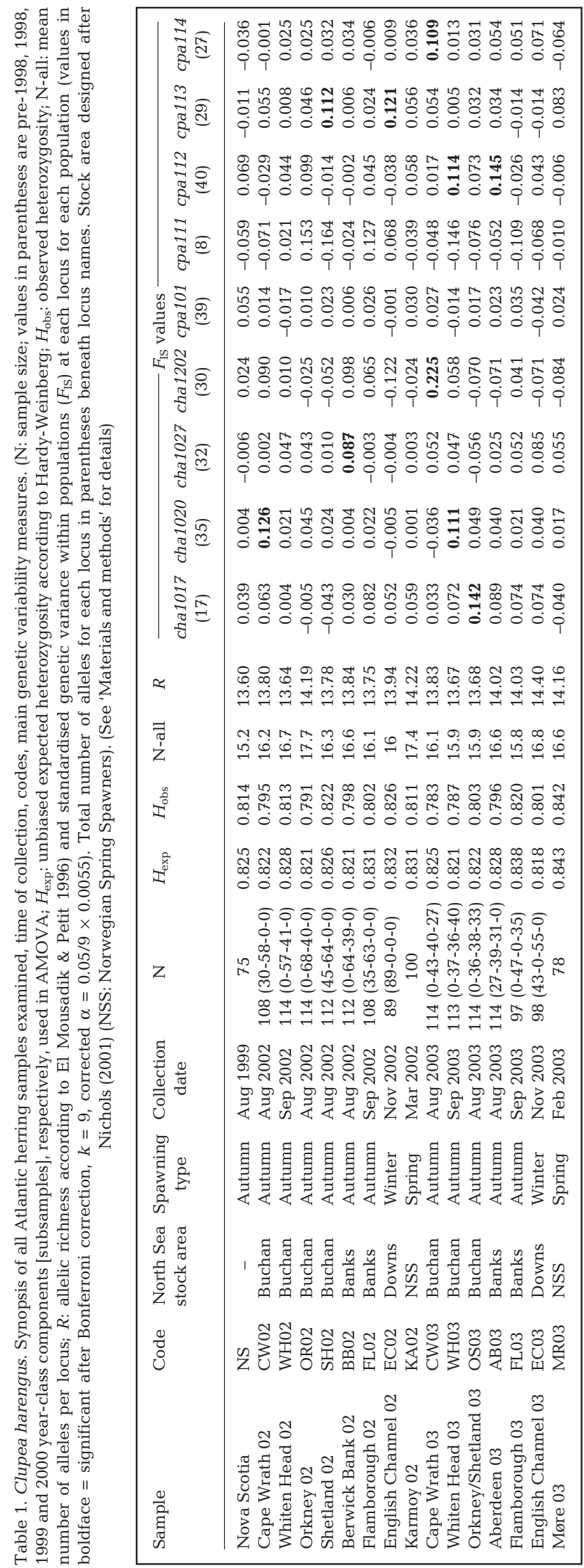

Table 2. Overall $F_{\mathrm{ST}}$ (standardised genetic variance between populations) in turn recalculated through jackknifing (omitting each locus with no replacement). Mean and standard error of jackknife estimator are also shown together with overall $F_{\text {ST }}$ values across all loci, including and excluding Canadian (Nova Scotia) sample, with relevant $95 \%$ bootstrap confidence limits. $F_{\mathrm{ST}}$ values for each locus are also shown

\begin{tabular}{|lcc|}
\hline Jackknifed $F_{\text {ST }}$ across loci & $\begin{array}{c}\text { Overall } \\
F_{\text {ST }}\end{array}$ & $\begin{array}{c}\text { Single-locus } \\
F_{\text {ST }}\end{array}$ \\
\hline Locus cha1017 omitted & 0.00117 & 0.0002 \\
Locus cha1020 omitted & 0.00096 & 0.0017 \\
Locus cha1027 omitted & 0.00095 & 0.0019 \\
Locus cha1202 omitted & 0.00101 & 0.0016 \\
Locus cpa101 omitted & 0.00122 & 0.0000 \\
Locus cpa111 omitted & 0.00100 & 0.0024 \\
Locus cpa112 omitted & 0.00093 & 0.0021 \\
Locus cpa113 omitted & 0.00128 & 0.0000 \\
Locus cpa114 omitted & 0.00112 & 0.0007 \\
Mean (SE) & $0.00106(0.00034)$ \\
Overall across 9 loci & $\mathbf{0 . 0 0 1 0 8}$ \\
Overall without Nova Scotia & $\mathbf{( 0 . 0 0 0 5 0 - 0 . 0 0 1 7 2 )}$ \\
& $\mathbf{0 . 0 0 0 8 9}$ \\
& $\mathbf{( 0 . 0 0 0 3 3 - 0 . 0 0 1 4 5 )}$ \\
\hline
\end{tabular}

and Norwegian samples from 2003 (EC03 and MR03) lying more peripherally. In the $D_{\mathrm{S}}$-based ordination (Fig. 2b), samples from the English Channel in 2002 and central North Sea collections (FL02, FL03, AB03) also occupy more external positions. The $R_{\mathrm{ST}}$-based ordination reduces the level of differentiation of the Møre 2003 sample and seems to emphasize the divergence of the 2 English Channel samples (Fig. 2c).

The matrices of genetic differentiation and geographic distance among samples were correlated in both years (Mantel test; 2002 data: $Z=0.19, \mathrm{r}=0.52$, $\mathrm{p}=0.004 ; 2003$ data: $Z=0.43, \mathrm{r}=0.58, \mathrm{p}=0.003$ ), suggesting the existence of a significant isolation by distance pattern, with geographic distance explaining about $30 \%$ of the pattern of genetic variation (Fig. 3). When pairwise values relative to the English Channel in 2002 and 2003 and the Norwegian sample in 2003 were removed, the association was lost (Mantel tests, $\mathrm{p}=\mathrm{ns})$. Moreover, none of the tests performed separately on males and females to test for sex-related differentiation yielded significant results.

\section{Year-class structure}

Year-class frequency distributions in the herring samples from 2002 (Fig. 4a) revealed the dominance of the 1998 and, to a lesser extent, 1999 cohorts throughout the central and northern North Sea, whereas yearclasses between 1995 and 1997, and between 1993 and 1994, dominated in the English Channel and the Norwegian Spring spawners respectively. Data from 2003 
Table 3. Clupea harengus. Population pairwise comparisons of $F_{\mathrm{ST}}$. Within-year comparisons are outlined (continuous line: 2002; dashed line: 2003). Values in boldface $=$ significant after sequential Bonferroni correction for multiple tests (correction applied with initial $k=28$ for 2002 samples, $k=21$ for 2003 , and $k=56$ for interannual comparison). Asterisks refer to values that were significant before applying correction $\left({ }^{*} p<0.05 ;{ }^{* *} p<0.01\right)$. Sample codes as in Table 1

\begin{tabular}{|c|c|c|c|c|c|c|c|c|c|c|c|c|c|c|c|c|}
\hline Sample & NS & СР02 & WH02 & SH02 & OR02 & BB02 & FL02 & EC02 & KA02 & CW03 & WH03 & OS03 & AB03 & FL03 & EC03 & MR03 \\
\hline NS & - & & & & & & & & & & & & & & & \\
\hline СР02 & $0.0023^{*}$ & & & & & & & & & & & & & & & \\
\hline WH02 & $0.0018^{*}$ & 0.0002 & & & & & & & & & & & & & & \\
\hline SH02 & 0.0016 & 0.0001 & 0.0000 & & & & & & & & & & & & & \\
\hline OR02 & $0.0029^{* *}$ & 0.0000 & 0.0000 & 0.0004 & & & & & & & & & & & & \\
\hline BB02 & $0.0028^{*}$ & 0.0004 & 0.0004 & 0.0000 & 0.0002 & & & & & & & & & & & \\
\hline FL02 & $0.0020^{*}$ & 0.0006 & 0.0005 & 0.0007 & 0.0015 & 0.0003 & & & & & & & & & & \\
\hline EC02 & $0.0034^{* *}$ & 0.0011 & $0.0020^{*}$ & 0.a0009 & 0.0010 & 0.0011 & 0.0006 & & & & & & & & & \\
\hline KA02 & $0.0020^{*}$ & 0.0000 & 0.0000 & 0.0006 & 0.0001 & 0.0000 & $0.0017^{*}$ & 0.0007 & & & & & & & & \\
\hline CW03 & 0.0017 & 0.0010 & 0.0000 & 0.0000 & 0.0000 & 0.0001 & 0.0010 & 0.0013 & 0.0004 & & & & & & & \\
\hline WH03 & $0.0026^{*}$ & 0.0000 & 0.0000 & 0.0000 & 0.0000 & 0.0002 & 0.0000 & 0.0010 & 0.0000 & 0.0000 & & & & & & \\
\hline OS03 & $0.0032^{* *}$ & 0.0000 & 0.0000 & 0.0000 & 0.0000 & 0.0004 & 0.0016 & 0.0005 & 0.0000 & 0.0003 & 0.0002 & & & & & \\
\hline AB03 & $0.0030^{* *}$ & $0.0021^{*}$ & 0.0006 & 0.0005 & 0.0002 & $0.0021^{*}$ & $00018^{*}$ & 0.0009 & $0.0016^{*}$ & 0.0014 & 0.0009 & 0.0004 & & & & \\
\hline FL03 & 0.0015 & 0.0011 & 0.0015 & $0.0023^{*}$ & 0.0006 & $0.0031^{* *}$ & $0.0019^{*}$ & 0.0002 & 0.0003 & 0.0006 & 0.0010 & 0.0000 & 0.0000 & & & \\
\hline $\mathrm{EC} 03$ & 0.0051 & 0.0012 & 0.0037 & 0.0017 & 0.0012 & $0.0022^{*}$ & 0.0061 & 0.0015 & 0.0011 & $\begin{array}{l}0.0038 \\
\end{array}$ & $0.0029^{* *}$ & 0.0005 & 0.0034 & 0.0036 & & \\
\hline MR03 & 0.0041 & $0.0024^{*}$ & $0.0027^{* *}$ & $0.0021^{*}$ & $0.0021^{*}$ & $0.0025^{*}$ & 0.0032 & $0.0019^{*}$ & 0.0001 & $0.00195^{*}$ & $0.0032^{* *}$ & $0.0023^{*}$ & 0.0037 & 0.0018 & $0.0027^{*}$ & $\cdots$ \\
\hline
\end{tabular}

(Fig. 4b) revealed recruitment into the central and northern North Sea populations of fish hatched in 2000, which do not seem to recruit into the English Channel aggregation. The Norwegian sample comprised considerably older individuals, also in 2003.
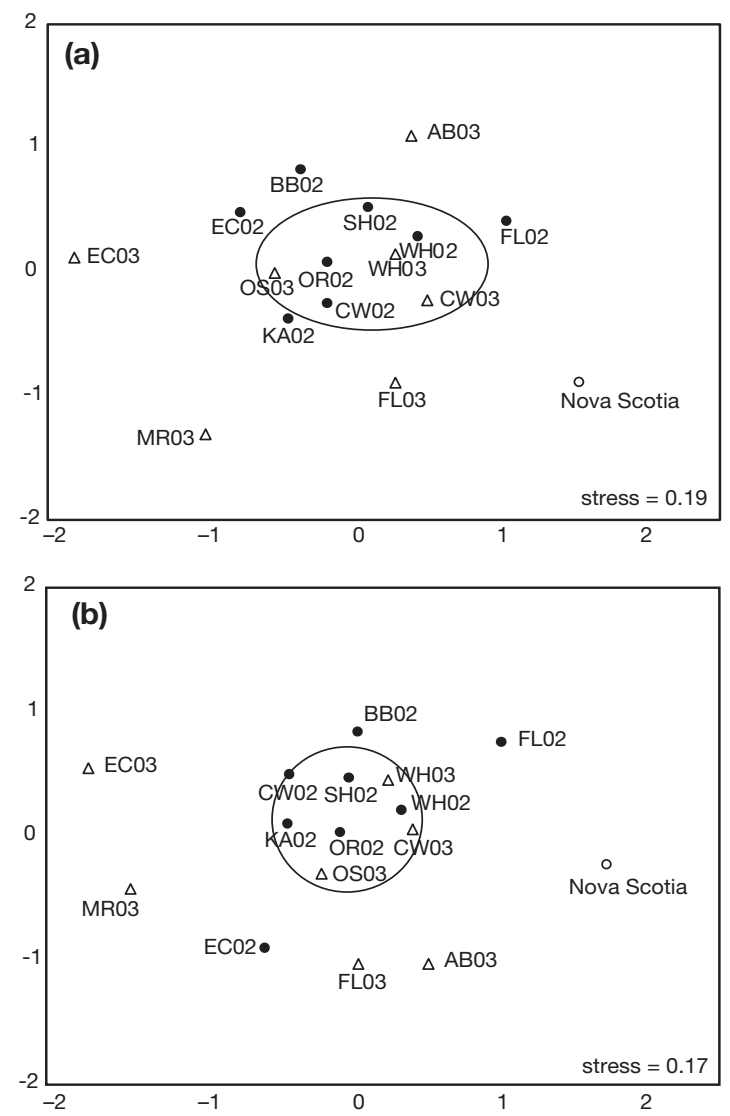

Tests of differentiation among age classes within samples did not reveal large differences. The only significant within-sample comparison was in the Aberdeen 2003 sample between the 1999 year-class and the $1997+$ age-group $\left(F_{\mathrm{ST}}=0.007 ; \mathrm{p}=0.01\right)$.

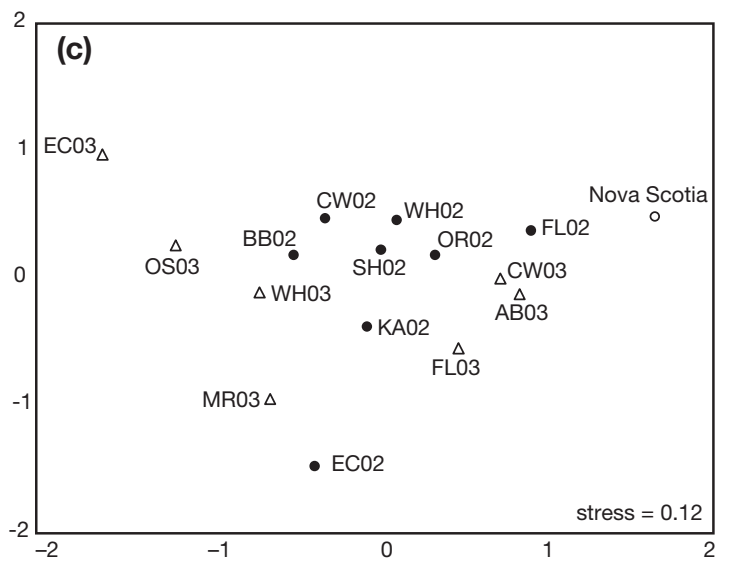

Fig. 2. Clupea harengus. MDS plots of samples based on different genetic measures: (a) $F_{\mathrm{ST},}$ (b) $D_{\mathrm{S},}$ (c) $R_{\mathrm{ST}}$. $(\bullet)$ Samples from 2002; $(\Delta)$ samples from 2003. Circles in (a) and (b) highlight homogeneity among samples off Northern Scotland. Sample codes as in Table 1 

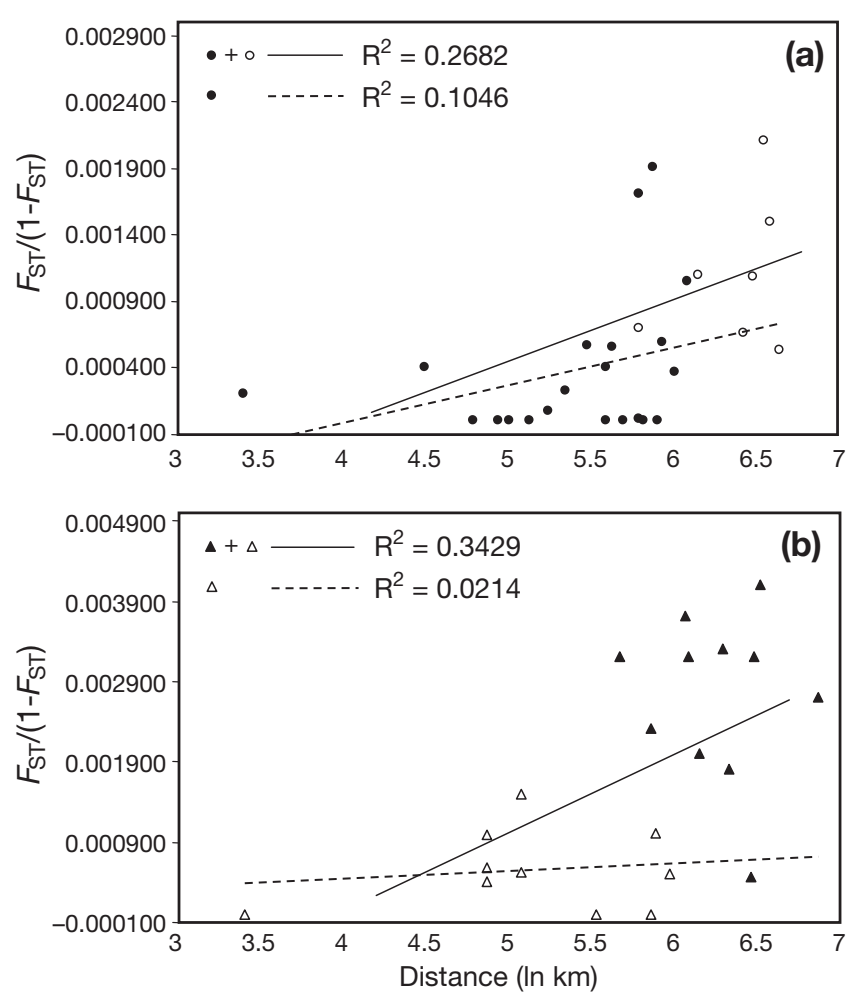

Fig. 3. Clupea harengus. Isolation-by-distance plots of pairwise $F_{\mathrm{ST}}$ values against geographical distance. (a) 2002; pairwise comparisons with $(\bullet+0)$ or without $(\bullet$ only) EC02. (b) 2003; pairwise comparisons with $(\Delta+\Delta)$ or without $(\Delta$ only) Samples EC03 and MR03. Continuous line: regression line for complete data set; dashed line: regression line for reduced data sets

Regional and year-class groupings

Subsamples composed of individuals from the same sample and year-class were subjected to 2 AMOVA designs (the Norwegian samples were not compared because of the entirely different age class composition). In the first analysis, the 'among year-classes' genetic variance $\left(F_{\mathrm{CT}}\right)$ was compared to the 'among subsamples' genetic variance $\left(F_{\mathrm{SC}}\right)$. This design yielded significant age-group structure in the 2002 collections, but not in the 2003 collections, in which more genetic variance was accounted for by differences between 'within year-class' subsets from different locations (Table 4). In the second analysis, we pooled samples into the 3 traditional stock regions: Buchan, Banks, and Downs (Table 1). Subtle, yet significant, regional structure was detected both in 2002 and $2003\left(F_{\mathrm{CT}}>\right.$ $F_{\text {SC) }}$ (Table 4).
Pooled 2002 and 2003 data

When pooling samples from 2002 and 2003, no detectable genetic differences were found between yearclasses $\left(F_{\mathrm{CT}}<F_{\mathrm{SC}}\right.$ all $\left.\mathrm{p}=\mathrm{ns}\right)$; genetic variance explained by geographical regions could be estimated, but its contribution was minimal and lower than that explained by subsamples within groups $\left(F_{\mathrm{CT}}=0.0007, \mathrm{p}<0.01\right.$.; $F_{\mathrm{SC}}=$ $0.0015, \mathrm{p}<0.001)$. Pooled Northern North Sea samples only (Cape Wrath, Whiten Head and Orkney-Shetland areas) were subject to another separate AMOVA to test whether structuring among year-classes was detectable. No evidence of any such structure was revealed $\left(F_{\mathrm{CT}}=\right.$ $0.0001 ; F_{\mathrm{SC}}=0.0002$, all $\left.\mathrm{p}=\mathrm{ns}\right)$.

Spatial analysis within year-classes and Bayesian analysis

We found no relationship between the age of spawning herring and the overall degree of spatial structure (Fig. 5). However, we found that the only overall $F_{\mathrm{ST}}$ values significantly different from zero were those of the 1999 year-class.

In both sampling years, the posterior probability distributions obtained through Bayesian computation provided support for the existence of a single North Sea herring spawning population, as the large majority of Monte Carlo iterations were consistent with a number of source populations $K=1$ (in 2002, $K=1, P=$ $0.980 ; K=2, P=0.019 ; K=3, P=0.001 ; K=4, P=0.000$. In 2003, $K=1, P=0.951 ; K=2, P=0.027 ; K=3, P=$ $0.018 ; K=4, P=0.004)$.

\section{Impact of population crashes}

Garza \& Williamson's M-ratio, calculated for each population, showed very high values, ranging from 0.986 (Cape Wrath, 2003) to 0.899 (English Channel, 2003), with an average value of 0.951 (variance 0.005), which is comparable to that reported for very stable populations, even assuming a strictly conservative single-step mutation model (Garza \& Williamson 2001). Simulation tests confirmed that the $M$-ratios were not significantly smaller than what would be

Table 4. Clupea harengus. Summary of analyses of molecular variance performed on North Sea samples collected in 2002 and 2003. $F_{\mathrm{CT}}$ : genetic variance among groups of samples (year-classes or regional areas); $F_{\mathrm{SC}}$ : genetic variance among subsamples within the defined groups

\begin{tabular}{|ccccc|}
\hline \multirow{2}{*}{ Year } & \multicolumn{2}{c}{ Year-class group structure } & \multicolumn{2}{c|}{ Regional group structure } \\
& $F_{\mathrm{CT}}$ & $F_{\mathrm{SC}}$ & $F_{\mathrm{CT}}$ & $F_{\mathrm{SC}}$ \\
\hline 2002 & $0.0014(\mathrm{p}<0.001)$ & $0.000(\mathrm{p}=\mathrm{ns})$ & $0.0007(\mathrm{p}<0.05)$ & $0.0004(\mathrm{p}=\mathrm{ns})$ \\
2003 & $0.0000(\mathrm{p}=\mathrm{ns})$ & $0.0022(\mathrm{p}<0.05)$ & $0.0016(\mathrm{p}<0.001)$ & $0.0013(\mathrm{p}<0.01)$ \\
\hline
\end{tabular}




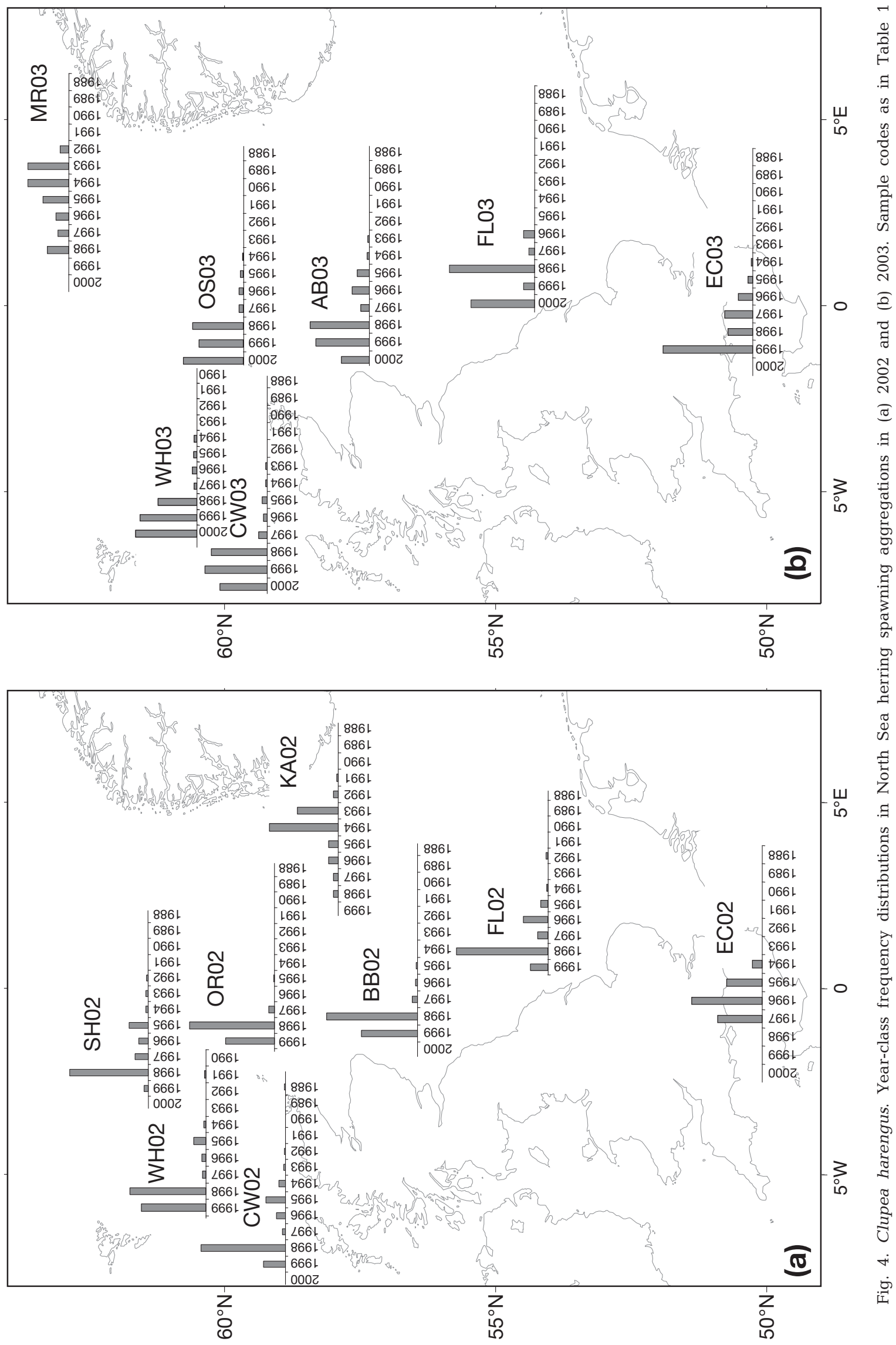




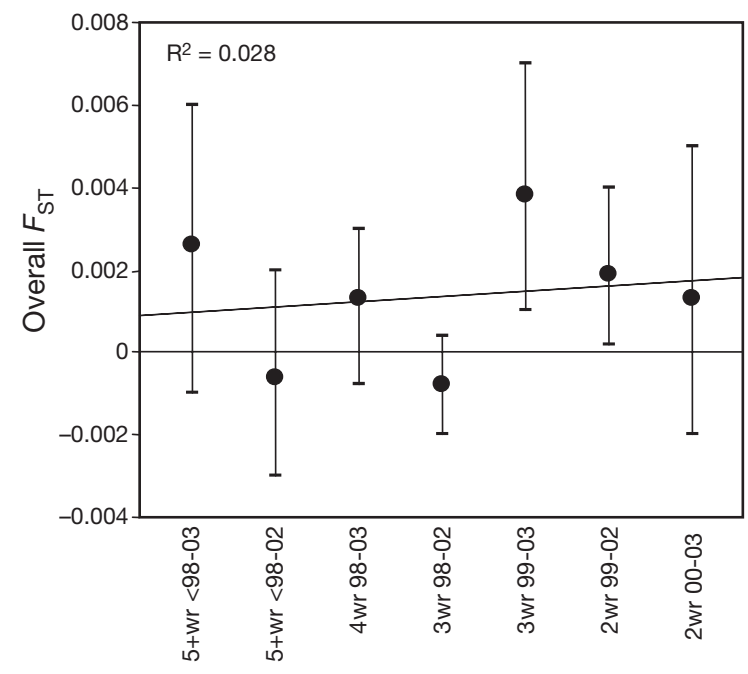

Fig. 5. Clupea harengus. Overall $F_{\mathrm{ST}}$ values calculated within each age-class (bars $=95 \%$ bootstrap confidence limits). Categories along $x$-axis labelled according to number of winter rings (wr) on otoliths, inferred year of hatching (pre-1998, $1998,1999,2000)$, and the sampling year (2002 or 2003), and ordered along age gradient (e.g. ' $3 \mathrm{wr}^{\prime}$ 'specimens caught in 2003 hatched in 1999, and are older than 2wr specimens hatched in the same year but collected in 2002)

expected for populations at equilibrium. The calculation performed on pooled North Sea data yielded a similarly high value: 0.959 (variance 0.004 ). Moreover, no evidence of genetic bottlenecks, as inferred from BOTTLENECK, was found in any of the 3 most numerous year-classes, or by conducting the test on pooled samples. Irrespective of the mutation model assumed, the distribution of allelic frequencies did not deviate from a normal L-shaped distribution, and all Wilcoxon tests were not significant.

\section{DISCUSSION}

\section{Spatio-temporal structure in the North Sea}

Most spawning aggregations in the North Sea were genetically indistinguishable from each other. In relatively few cases we detected a signal of differentiation, which always involved aggregations from the English Channel and the Norwegian coast. The presence of an isolation-by-distance pattern over 2 consecutive years suggests that the observed trend is biologically significant (Waples 1998, Palumbi 2003), and essentially depends on the effect of the most divergent English Channel aggregation and (only in 2003) on the Norwegian sample (Fig. 3). The present data do not allow the unambiguous identification of well-resolved, spatially separated population units. Moreover, the use of
Bayesian methodology to infer population substructure gave support to the existence of 1 single source population in the North Sea; although this result may depend on the resolution limit of such computational approaches, which have so far been shown to perform well only when differentiation is conspicuous (Manel et al. 2005).

The view of the strong subdivision of Atlantic herring into consistently distinct, identifiable populations (Iles \& Sinclair 1982) was not supported by earlier genetic studies (Kornfield et al. 1982, Ryman et al. 1984, Hauser et al. 2001) and was again challenged by recent molecular data (McPherson et al. 2003, 2004), which revealed a subtle spatio-temporal patchiness lacking clear geographical structuring in western Atlantic herring.

Many samples off northern Scotland proved to be spatially and temporally undistinguishable (Cape Wrath, Whiten Head, Orkney, Shetland), suggesting a lack of spatio-temporal structure within the herring population unit traditionally referred to as the 'Buchan' stock (Nichols 2001). This is further corroborated by the fact that, as tested by AMOVA, year-class composition did not account for any genetic differentiation within this population group. These herring aggregations spawn in areas very close to their mixed summerfeeding aggregations (ICES 2004), and migrate relatively short distances in August to reach the spawning grounds.

Conversely, we did not find such consistent homogeneity in the 'Banks' herring (central North Sea) and the spring spawners from the Norwegian coasts (Karmøy and Møre). In fact, even though it was not always possible to collect spawners from exactly the same locations in both years (i.e. Berwick Bank in 2002 and Aberdeen Bank in 2003, Karmøy in 2002 and Møre in 2003), the spatial pattern of genetic variation in these areas showed some degree of temporal instability. In particular, the 2002 Karmøy sample, albeit showing the age structure (Fig. 4) and the general phenotypic characteristics (data not shown) typical of Norwegian spring spawners, does not diverge genetically from the northern North Sea, whereas Møre in 2003 appears clearly differentiated. Similarly, samples of central North Sea 'Banks' herring do not cluster together, and in 1 collection (Aberdeen 2003) the older spawners appear significantly different from younger fish. Further evidence of temporal instability of more peripheral spawning aggregations is also suggested by the fact that, while the AMOVA could detect subtle yearclass structure in 2002 samples and regional group structure in both 2002 and 2003, when samples from both years were pooled and re-examined, no genetic variance was explained by higher hierarchical groupings (year-classes or geographical regions). 
Based on microsatellite data, it appears that, while the 'Buchan' herring stock in the northern North Sea may represent a stable, identifiable unit, other spawning aggregations, albeit revealing some degree of differentiation, do not have similar integrity, making the interpretation of the finer stock structure in the North Sea problematic. Such annual variation in peripheral locales may be caused by the interaction of 3 main factors. Firstly, the complex dynamics of abandonment/ recolonisation of traditional spawning sites, which depend on environmental changes, population fluctuations and herring behaviour, have recently affected in particular the central and southern North Sea (Corten 1999). Secondly, despite the high-resolution power of the markers and sample sizes used in this study, for some samples close to the limit of this resolution it is difficult to assess with confidence the biological significance of the observed variation (Waples 1998). Finally, large annual fluctuations of new year-classes recruiting into the spawning population may also play a role (Fig. 4). In particular, when data were analysed within each year-class separately, it was evident that most differentiation originated from samples hatched in 1999 (Fig. 5). The 1999 year-class was considerably smaller (about half the size) than both the 1998 and 2000 yearclasses (ICES 2004), although, the present data are not sufficient to test rigorously whether the signal of genetic structuring may be to some extent related to year-class strength. On the other hand, no support was found for Corten's (2002) hypothesis, which postulated that the extent of genetic structuring could be related to the contribution of older, philopatric individuals to the spawning aggregations.

\section{Eastern versus western Atlantic}

The sole western Atlantic sample analysed was less divergent from the eastern collections than might have been expected based on its geographic distance, and was within the same range of $F_{\mathrm{ST}}$ values observed among North Sea samples. The only other available study comparing eastern and western Atlantic herring samples using similar methodologies is that of McPherson et al. (2004). These authors focused on western Atlantic herring and compared them with some eastern Atlantic samples, also using 9 microsatellites (5 of which were also employed in this study). They reported an overall $F_{\mathrm{ST}}$ value among all locales of 0.002, and their $F_{\mathrm{ST}}$-based MDS plot showed that herring from the Celtic Sea and Iceland were closely grouped with the Nova Scotian samples, with only the Baltic herring clearly distinct from all other samples (McPherson et al. 2004). This is in agreement with our finding that transoceanic measurable differentiation is of the same order of magnitude as that observed within the North Sea. Baltic herring data are not presented here, but preliminary results show that they are a clearly distinct population unit (HERGEN unpubl.: www.hull.ac.uk/hergen/). In contrast, and for reasons that remain unclear, McPherson et al. (2004) reported (their Table 2) an $F_{\mathrm{ST}}$ value between pooled western samples and eastern Atlantic populations close to 0.07 , indicating markedly higher transoceanic differentiation. Additional samples from the western Atlantic for direct comparison would clearly be of value.

It is worth noting that when population sizes are very large and mutation rate high, size homoplasy at microsatellite loci might reduce the level of divergence between populations (Estoup et al. 2002). However, with the aid of other genetic distance measures believed to be less sensitive to homoplasy and whose values are known to saturate less quickly than $F_{\mathrm{ST}}$ (such as $D_{\mathrm{S}}$ and $R_{\mathrm{ST}}$ ) (Balloux \& Lugon-Moulin 2002, Kalinowski 2002, O'Reilly et al. 2004), consistently low estimates of differentiation between the Nova Scotian and North Sea samples were observed. A study by Hutchinson et al. (2001) illustrated that similarly polymorphic microsatellite markers in cod can indeed detect an east-west Atlantic divergence up to 10 times higher than the differentiation within the North Sea. Further analyses currently being carried out by the present authors are expected to elucidate deeper phylogeographic aspects of Atlantic herring across its entire distribution range.

\section{Demographic changes}

The North Sea herring has been affected by recent dramatic population fluctuations. Between 1974 and 1978, fishing pressure reduced the spawning stock to $2 \%$ of its level in the 1960s (ICES 2004), while more recently (1993 to 1996) a similar initial decline was halted by management actions at about $23 \%$ of the higher level of spawning biomass. Such dramatic, recent population collapses may have been followed by extensive recolonisation events during the early years of recovery (Corten 1999). In such case, the lack of marked differentiation revealed by the present study may derive from a non-equilibrium expansion phase of current herring populations. However, we did not find any empirical evidence that the genetic diversity of North Sea herring had been affected by recent bottlenecks. Both Garza \& Williamson's (2001) and Piry et al.'s (1999) approaches indicated that allelic frequencies in North Sea herring were not influenced by the recent stock collapses in the 1970s and the mid-1990s. It should be mentioned that even 
at the time of lowest spawning stock biomass, North Sea herring still comprised hundreds of millions of fish, even assuming an hypothetically low $N_{\mathrm{e}}: N$ (effective population size:census size) ratio of $10^{-5}$ (Hutchinson et al. 2003, Hoarau et al. 2005), this represents, in population genetics terms, a population too large for genetic drift to be detected after a few generations (Nei 1987, Kalinowski 2002). The evidence of weak but significant differentiation of the English Channel stock cannot simply be explained by a recent divergence event after the stock collapse in the 1970s and rapid decline in the 1990s: if drift is the main force in shaping the pattern, its history has to be traced further back in time, while if selective forces are involved, these may to some extent be linked to the fact that the English Channel represents the southern limit of the species' distribution.

\section{North Sea herring metapopulation and fisheries management}

Despite the robust sampling design (large sample size, analysis of spawning individuals, temporal repeats) and the high statistical power of our markers (significance of $F_{\mathrm{ST}}$ could be detected below 0.002), we detected little evidence for the existence of genetically discrete North Sea herring populations. Such findings do not contradict the current view of North Sea herring as a unit-stock (ICES 2004), although this would not necessarily exclude a significant demographic independence of different spawning aggregations, as large populations require many generations to attain migration/drift equilibrium and reveal any detectable signal of genetic differentiation (Hedrick 2000).

When genetic evidence is employed to support fisheries management, it is important to recognise that a very limited exchange of migrants per generation is sufficient to obscure genetic structuring (Waples 1998). While such low migration rates are generally sufficient to guarantee population connectivity over evolutionary timescales, they are a negligible force for rebuilding depleted stocks over a timescale of interest to fisheries. In this light, the recorded divergence of the English Channel aggregations, along with their different recruitment dynamics and other previously known lifehistory traits (Zijlstra 1969), strengthens the view that the Downs herring should be managed separately from others in the North Sea.

Over a broader timescale, it is important to note that, as in other clupeoids (Grant \& Bowen 1998, Lecomte et al. 2004), herring population dynamics naturally tend to be characterised by marked fluctuations in biomass and recruitment (i.e. 'boom and bust') (ICES 2004) that generally reflect natural environmental variation
(Axenrot \& Hansson 2003). Furthermore, most of the distribution range of Atlantic herring in the North Sea only achieved its present character in the last few thousand years, following repeated dramatic glacial expansion and contraction (Hewitt 2000). Since such largescale processes on presumably large populations are unlikely to attain equilibrium, and in view of the 'bethedging' life-history strategy of Atlantic herring in maximising recruitment success over large geographical scales (McQuinn 1997), it is perhaps unlikely that this species would maintain a structured set of stable, well-differentiated and genetically identifiable spawning aggregations over evolutionary timescales. Even so, in view of the uncoupling of genetically effective migration rates and demographic independence (Carvalho \& Hauser 1994), the observed heterogeneity in herring population structure should not be ignored across the shorter timescales of relevance to exploitation. Collective evidence indicates that McQuinn's (1997) metapopulation concept appears to be a good framework for interpreting North Sea herring structure, although the apparently weak association between phenotypic and genetic traits in Clupea harengus will limit the potential for genetic identification of stocks at local scales. Nevertheless, the pattern of isolation-by-distance suggests that geographically and/or ecologically divergent groups may still be detectable through a judicious integration of phenotypic and genotypic approaches.

After more than a century of research, a thorough understanding of Atlantic herring population structure still remains one of the big challenges in marine biology: further investigations, including (1) the exhaustive comparison of spawning aggregations across the entire geographic range of Atlantic herring, (2) the employment of archived historical samples to examine the long-term temporal dynamics of spatial differentiation, (3) the use of selectively non-neutral genetic markers to investigate aspects of local adaptation, (4) the analysis of feeding aggregations, and (5) a robust integration with other approaches, would probably provide the necessary framework to meet this challenge.

Acknowledgements. We are very grateful to all the fisheries observers involved in the sampling campaigns throughout the North Sea and to Arran McPherson for providing the Canadian sample. We thank F. Neat and D. Weetman for critical reading of an earlier draft of the manuscript, C. Garza for his feedback on M_P_VAL, and E. Norlin and B. Jönsson for assistance in the laboratory. The manuscript also benefited from the focused and wise observations of 2 anonymous referees. This work is part of the research project HERGEN (www.hull.ac.uk/hergen/), funded by the European Union within the Framework Programme 5, and has benefited considerably from continuous dialogue and exchange of ideas among all the participants in the project. 


\section{LITERATURE CITED}

Anonymous (1975) Report of the ICES working group on the Bløden tagging experiment, 1969/70. Int Counc Explor Sea Coop Res Rep 47:136

Axenrot T, Hansson S (2003) Predicting herring recruitment from young-of-the-year densities, spawning stock biomass, and climate. Limnol Oceanogr 48:1716-1720

Balloux F, Lugon-Moulin N (2002) The estimation of population differentiation with microsatellite markers. Mol Ecol 11:155-165

Belkhir K, Borsa P, Chikhi L, Raufaste N, Bonhomme F (2000) GENETIX: logiciel sous Windows pour la génétique des populations. Laboratoire Génome, Populations, Interactions CNRS UMR 5000, Université de Montpellier II, Montpellier

Blaxter JHS, Hunter JR (1982) The biology of clupeoid fishes. Adv Mar Biol 20:1-223

Carvalho GR, Hauser L (1994) Molecular genetics and the stock concept in fisheries. Rev Fish Biol Fish 4:326-350

Corten A (1999) The reappearance of spawning herring on Aberdeen Bank (North Sea) in 1983 and its relationship to environmental conditions. Can J Fish Aquat Sci 56: 2051-2061

Corten A (2002) The role of 'conservatism' in herring migrations. Rev Fish Biol Fish 11:339-361

Cushing DH (1967) The grouping of herring populations. J Mar Biol Assoc UK 47:193-208

Dawson KJ, K Belkhir (2001) A Bayesian approach to the identification of panmictic populations and the assignment of individuals. Genet Res 78:59-77

Di Rienzo A, Peterson AC, Garza JC, Valdez AM, Slatkin M, Freimer NB (1994) Mutational processes of simplesequence repeat loci in human populations. Proc Natl Acad Sci USA 91:3166-3170

El Mousadik A, Petit RJ (1996) High level of genetic differentiation for allelic richness among populations of the argan tree [Argania spinosa (L.) Skeels] endemic to Morocco. Theor Appl Genet 92:832-839

Engelhard GH, Heino M (2004) Maturity changes in Norwegian spring-spawning herring Clupea harengus: compensatory or evolutionary responses? Mar Ecol Prog Ser 272: 245-256

Estoup A, Jarne P, Cornuet JM (2002) Homoplasy and mutation model at microsatellite loci and their consequences for population genetics analysis. Mol Ecol 11: 1591-1604

Excoffier L, Smouse PE, Quattro JM (1992) Analysis of molecular variance inferred from metric distances among DNA haplotypes-application to human mitochondrial-DNA restriction data. Genetics 131:479-491

Garza JC, Williamson EG (2001) Detection of reduction in population size using data from microsatellite loci. Mol Ecol 10:305-318

Goodman SJ (1997) RsT-CALC: a collection of computer programs for calculating estimates of genetic differentiation from microsatellite data and determining their significance, Version 2.2. Mol Ecol 6:881-885

Grant WS (1984) Biochemical population genetics of Atlantic herring, Clupea harengus. Copeia 2:357-364

Grant WS, Bowen BW (1998) Shallow population histories in deep evolutionary lineages of marine fishes: insights from sardines and anchovies and lessons for conservation. J Hered 89:415-426

Hastings A, Harrison S (1994) Metapopulation dynamics and genetics. Annu Rev Ecol Syst 25:167-188

Hauser L, Ward RD (1998) Population identification in pelagic fish: the limits of molecular markers. In: Carvalho GR (ed) Advances in molecular ecology. IOS Press, Amsterdam, p 191-224

Hauser L, Turan C, Carvalho GR (2001) Haplotype frequency distribution and discriminatory power of two mtDNA fragments in a marine pelagic teleost (Atlantic herring, Clupea harengus). Heredity 87:621-630

Hauser L, Adcock GJ, Smith PJ, Ramirez JHB, Carvalho GR (2002) Loss of microsatellite diversity and low effective population size in an overexploited population of New Zealand snapper (Pagrus auratus). Proc Natl Acad Sci USA 99:11742-11747

Hedrick PW (2000) Genetics of populations. Jones \& Bartlett, London

Hewitt G (2000) The genetic legacy of the Quaternary ice ages. Nature 405:907-913

Hoarau G, Boon E, Jongma DN, Ferber S and 5 others (2005) Low effective population size and evidence for inbreeding in an overexploited flatfish, plaice (Pleuronectes platessa L.). Proc R Soc Lond Ser B 272:497-503

Hutchinson WF, Carvalho GR, Rogers SI (2001) Marked genetic structuring in localised spawning populations of cod (Gadus morhua) in the North Sea and adjoining waters, as revealed by microsatellites. Mar Ecol Prog Ser 223:251-260

Hutchinson WF, van Oosterhout C, Rogers SI, Carvalho GR (2003) Temporal analysis of archived samples indicates marked genetic changes in declining North Sea cod (Gadus morhua). Proc R Soc Lond Ser B 270:2125-2132

ICES (2004) Report of the Herring Assessment Working Group for the Area South of $62^{\circ}$. Int Counc Explor Sea Comm Meet ACF 18:551

Iles TD, Sinclair M (1982) Atlantic herring: stock discreteness and abundance. Science 215:627-633

Kalinowski ST (2002) Evolutionary and statistical properties of three genetic distances. Mol Ecol 11:1263-1273

Knutsen H, Jorde PE, Andre C, Stenseth NC (2003) Finescaled geographical population structuring in a highly mobile marine species: the Atlantic cod. Mol Ecol 12: 385-394

Kornfield I, Sidell B, Gagnon P (1982) Stock definition in Atlantic herring, (Clupea harengus): genetic evidence for discrete fall and spring spawning populations. Can J Fish Aquat Sci 39:1610-1621

Kritzer JP, Sale PF (2004) Metapopulation ecology in the sea: from Levins' model to marine ecology and fisheries science. Fish Fish 5:131-140

Lecomte F, Grant WS, Dodson JJ, Rodriguez-Sanchez R, Bowen BW (2004) Living with uncertainty: genetic imprints of climate shifts in East Pacific anchovy (Engraulis mordax) and sardine (Sardinops sagax). Mol Ecol 13: 2169-2182

Luikart G, Allendorf FW, Cornuet JM, Sherwin WB (1998) Distortion of allele frequency distributions provides a test for recent population bottlenecks. J Hered 89:238-247

Manel S, Gaggiotti OE, Waples RS (2005) Assignment methods: matching biological questions with appropriate techniques. Trends Ecol Evol 20:136-142

Mantel N (1967) The detection of disease clustering and a generalized regression approach. Cancer Res 27:209-220

McPherson AA, O'Reilly PT, McParland TL, Jones MW, Bentzen P (2001) Isolation of nine novel tetranucleotide microsatellites in Atlantic herring (Clupea harengus). Mol Ecol Notes 1:31-32

McPherson AA, Stephenson RL, Taggart CT (2003) Genetically different Atlantic herring Clupea harengus spawning waves. Mar Ecol Prog Ser 247:303-309 
McPherson AA, O'Reilly PT, Taggart CT (2004) Genetic differentiation, temporal stability, and the absence of isolation by distance among Atlantic herring populations. Trans Am Fish Soc 133:434-446

McQuinn IH (1997) Metapopulations and the Atlantic herring. Rev Fish Biol Fish 11:339-361

Nei M (1978) Estimation of average heterozygosity and genetic distance from a small number of individuals. Genetics 89:583-590

Nei M (1987) Molecular evolutionary genetics. Columbia University Press, New York

Nichols JH (2001) Management of North Sea herring and prospects for the new millenium. In: Funk F, Blackburn J, Hay D (eds) Herring: expectations for a new millenium. University of Alaska Sea Grant, Fairbanks, AK, p 645-665

Nielsen EE, Nielsen PH, Meldrup D, Hansen MM (2004) Genetic population structure of turbot (Scophthalmus maximus L.) supports the presence of multiple hybrid zones for marine fishes in the transition zone between the Baltic Sea and the North Sea. Mol Ecol 13:585-595

Olsen JB, Lewis CJ, Kretchmer EJ, Wilson SL, Seeb JE (2002) Characterization of 14 tetranucleotide microsatellite loci derived from Pacific herring. Mol Ecol Notes 2:101-103

O'Reilly PT, Canino MF, Bailey KM, Bentzen P (2004) Inverse relationship between $F_{\mathrm{ST}}$ and microsatellite polymorphism in the marine fish, walleye pollock (Theragra chalcogramma): implications for resolving weak population structure. Mol Ecol 13:1799-1814

Palumbi SR (2003) Population genetics, demographic connectivity and the design of marine reserves. Ecol Appl 13: S146-S158

Piry S, Luikart G, Cornuet JM (1999) BotTLENECK: a computer program for detecting recent reductions in the effective population size using allele frequency data. J Hered 90: 502-503

Raymond M, Rousset F (1995) GENEPOP (version 1.2): a population genetics software for exact tests and ecumenicism. J Hered 86:248-249

Rousset F (1997) Genetic differentiation and estimation of gene flow from $F$-statistics under isolation by distance. Genetics 145:1219-1228

Ruzzante DE, Taggart CT, Cook D (1998) A nuclear DNA basis for shelf- and bank-scale population structure in northwest Atlantic cod (Gadus morhua): Labrador to Georges Bank. Mol Ecol 7:1663-1680

Ruzzante DE, Taggart CT, Cook D (1999) A review of the evidence for genetic structure of cod (Gadus morhua) populations in the NW Atlantic and population affinities of larval cod off Newfoundland and the Gulf of St. Lawrence. Fish Res 43:79-97

Ryman N, Lagercrantz U, Andersson L, Chakraborty R, Rosen-

Editorial responsibility: Roger Hughes (Contributing Editor), Bangor, UK berg R (1984) Lack of correspondence between genetic and morphologic variability patterns in Atlantic herring (Clupea harengus). Heredity 53:687-704

Schneider S, Roessli D, Excoffier L (2000) Arlequin, Version 2.000: a software for population genetics analysis. Genetics and Biometry Laboratory. University of Geneva, Geneva

Shaw PW, Turan C, Wright JM, O'Connell M, Carvalho GR (1999) Microsatellite DNA analysis of population structure in Atlantic herring (Clupea harengus), with direct comparison to allozyme and mtDNA RFLP analyses. Heredity 83: 490-499

Slatkin M (1993) Isolation by distance in equilibrium and nonequilibrium populations. Evolution 47:264-279

Slatkin M (1995) A measure of population subdivision based on microsatellite allele frequencies. Genetics 139:457-462

Smedbol RK, McPherson A, Hansen MM, Kenchington E (2002) Myths and moderation in marine 'metapopulations'? Fish Fish 3:20-35

Smith WG, Jamieson A (1986) Stock discreteness in herring: a conceptual revolution. Fish Res 4:223-234

Truett GE, Heeger P, Mynatt RL, Truett AA, Walker JA, Warman ML (2000) Preparation of PCR-quality mouse genomic DNA with hot sodium hydroxide and tris (HotSHOT). Biotechniques 29:52-54

Turan C, Carvalho GR, Mork J (1998) Molecular genetic analysis of Atlanto-Scandian herring (Clupea harengus) populations using allozymes and mitochondrial DNA markers. J Mar Biol Assoc UK 78:269-283

Turner TF, Wares JP, Gold JR (2002) Genetic effective size is three orders of magnitude smaller than adult census size in an abundant, estuarine-dependent marine fish. Genetics 162:1329-1339

van Oosterhout C, Hutchinson WF, Mills DPM, Shipley P (2004) MiCRO-CHECKER: software for identifying and correcting genotyping errors in microsatellite data. Mol Ecol Notes 4:535-538

Waples RS (1998) Separating the wheat from the chaff: patterns of genetic differentiation in high gene flow species. J Hered 89:438-450

Weir BS, Cockerham CC (1984) Estimating F-statistics for the analysis of population structure. Evolution 38:1358-1370

Wheeler JP, Winters GH (1984) Homing of Atlantic herring (Clupea harengus harengus) in Newfoundland waters as indicated by tagging data. Can J Fish Aquat Sci 41: 108-117

Whitehead PJP (1985) King herring: his place amongst the clupeoids. Can J Fish Aquat Sci 42: S3-S20

Wirth T, Bernatchez L (2001) Genetic evidence against panmixia in the European eel. Nature 409:1037-1040

Zijlstra JJ (1969) On the 'racial' structure of North Sea autumnspawning herring. J Cons Int Explor Mer 33:67-80

Submitted: May 26, 2005; Accepted: July 15, 2005

Proofs received from author(s): November 8, 2005 